ANIMAL USE $\mid \ln 2013$, fundamental biology accounted for most animal experiments in the United Kingdom.

\begin{tabular}{llrr|}
\hline & & & \\
2 MILLION PROCEDURES* & & Veterinary \\
Fundamental & Human medicine & medicine & Other \\
biological research & or dentistry & $8 \%$ & $3 \%$ \\
$\mathbf{5 8 \%}$ & $26 \%$ & $3 \%$ \\
& & \\
\end{tabular}

Toxicological and related evaluations

*Breeding procedures such as genetic modification not included.
- determine sample size, even though both publishing groups had endorsed guidelines to improve reporting standards (D. Baker et al. PLoS Biol. 12, e1001756; 2014).

Animals feature in a wide range of experiments (see 'Animal use'), many of which are designed to test drugs before trials are done in people. The effects that researchers are looking for in these preclinical studies are often subtle, and 'power calculations' are needed to reveal the number of animals needed to show an effect. But an international academic partnership called the CAMARADES project (Collaborative Approach to Meta Analysis and Review of Animal Data from Experimental Studies), has shown that many animal studies are underpowered: studies in stroke, for example, are typically powered at between $30 \%$ and $50 \%$, meaning that there is just a $30-50 \%$ chance of detecting a biological effect if it exists.

Malcolm Macleod, a neuroscientist at the University of Edinburgh, UK, blames, among other things, a lack of training and support in experimental design, as well as limited funds: animals are expensive to work with.

Some say that the pressure to 'reduce' may be one of the reasons for small experiments, but others counter that this is a misinterpretation of the 3 Rs because small experiments are ethically problematic if they have low statistical power.

The problem is not limited to Britain: last year, Francis Collins, director of the US National Institutes of Health (NIH), and Lawrence Tabak, NIH deputy director, warned about a lack of reproducibility in preclinical research and mentioned a dearth of sample-size calculations as one of the problems (see Nature 505, 612-613 2014).

The situation infuriates animal-welfare proponents. "It's completely unethical to use animals in studies that aren't properly designed," says Penny Hawkins, head of the research-animals department at the Royal Society for the Prevention of Cruelty to Animals in Southwater, UK.

Boosting the number of animals in specific experiments need not mean more animals are used overall because multiple small experiments can often be replaced by fewer, larger ones "One potential implication is we need to ask for money to do larger studies," says Marcus Munafò, a psychologist at the University of Bristol, UK.

Another way to increase sample sizes would be to link up researchers working on similar topics. Munafò notes that this is what geneticists now do for studies that require scanning a large number of genomes. "That template already exists," he says. "The question is, how do you initiate that cultural change?"

More immediately, du Sert is developing an online tool for the NC3Rs that will help researchers to design robust studies. "We're not blaming anyone for the way they were doing things before," she adds. "That was the practice at the time." - SEE EDITORIALP.263

\title{
Canadians baulk at reforms to health-research agency
}

\section{Biomedical-funding revamp threatens to marginalize under-represented researchers.}

\section{BY SARA REARDON}

$\mathrm{T}$ he biggest overhaul in the 15-year history of the Canadian Institutes of Health Research (CIHR) was meant to rescue biomedical researchers from the endless grant applications and Byzantine peer-review processes that had become a feature of the cash-strapped agency. "The research community was complaining bitterly," says Alain Beaudet, president of the CIHR in Ottawa. "They begged me to make changes."

But now that reality is kicking in, many researchers worry that the changes - which modify how grants are awarded, restructure advisory boards and reallocate the money funnelled through the 13 virtual institutes that comprise the CIHR — will marginalize some fields and hurt early-career researchers.

Beaudet says that the plans have been in place for some time, but many researchers - particularly those on the institutes' scientific advisory boards - complain that the CIHR has failed to communicate the changes adequately, and that the number of simultaneous reforms is overwhelming.

"We're a little bit stunned," says Gillian Einstein, a cognitive neuroscientist at the University of Toronto and chair of the board that advises the CIHR's Institute of Gender Health. "I'm not sure the groundwork was laid so we'd understand what was happening."

Each institute has its own advisory board with up to 12 members, and receives a dedicated allotment of about Can $\$ 8.5$ million (US\$6.7 million) from the CIHR's Can\$1-billion annual research budget. In the 2016 budget, these outlays will be cut in half, with the savings going into a common fund. To access this new funding source, institutes will have to work together to design cross-disciplinary initiatives that have extra support from a funding partner such as a charity, institution or company. Beaudet says that the CIHR will be responsible for finding many of these partners.

The CIHR also plans to eliminate most of the scientific advisory boards, leaving only three or four panels, which will advise several institutes each. An internal panel is still evaluating the plan, which would not take effect before April 2016. Nearly all of the advisory boards are protesting the changes. "If you're doing well and have some vision, and someone took half your toolset away, I'd say the rug was pulled out," says Anthony Jevnikar, a nephrologist at Western University in London, Ontario, who chairs the advisory board for the Institute of Infection and Immunity.

\section{BAR TO ENTRY}

Feathers are also being ruffled by changes to the CIHR's system for awarding grants to proposals submitted by researchers. In July, 
the agency plans to hand out the first set of awards under a pilot system that divides about half of its research budget between two mechanisms. One of these, the Foundation Scheme, gives seven years of guaranteed funding to established researchers and five years to early-career investigators. Grant recipients can use the money for any project, but are barred from receiving other CIHR funding. The second mechanism, the Project Scheme, awards smaller grants for specified work over a shorter period.

But researchers who have been reviewing the first set of applications under the new system see potential problems, particularly for early-career researchers, who often have difficulty showing enough preliminary data to justify specific projects or enough of a track record to win an openended grant. New investigators submitted about $40 \%$ of the 1,366 grant applications for the Foundation Scheme's pilot round, but they were involved with less than $20 \%$ of the 467 applications that made it through the first phase of peer review. "Young researchers are left out in the cold," says Jim Woodgett, a molecular biologist at Mount Sinai Hospital in Toronto.

Some institutes also feel imperilled by the changes. Researchers supported by the Institute of Aboriginal Peoples' Health (IAPH) say that they have few funding options outside the CIHR, and would not find it easy to interest external partners in providing support so that they could receive money through the cross-disciplinary common fund. Their field is relatively new and they are under-represented among public-health researchers, so they feel disadvantaged if they have to compete against other institutes for money and for spots on an advisory board that will also oversee other institutes. "We're losing our distinctive voice," says Frederic Wien, a sociologist at Dalhousie University in Halifax who studies aboriginal health.

Such concerns are exactly why the reforms are taking place, says Beaudet: "There were not enough collaborations between institutes." For instance, he says, the other 12 institutes assumed that they did not need to worry about aboriginal peoples' health, because the IAPH would cover all relevant research. The other institutes' inattention to indigenous peoples' health is a huge problem, Beaudet adds.

Wien says that the CIHR has not been responsive to complaints over the past several years. He and others are also concerned that the agency might eliminate some institutes altogether. The 13 divisions have existed since the CIHR was founded, but Beaudet says that, by law, external and internal panels must review the institutes every five years; it has always been possible that some could be eliminated.

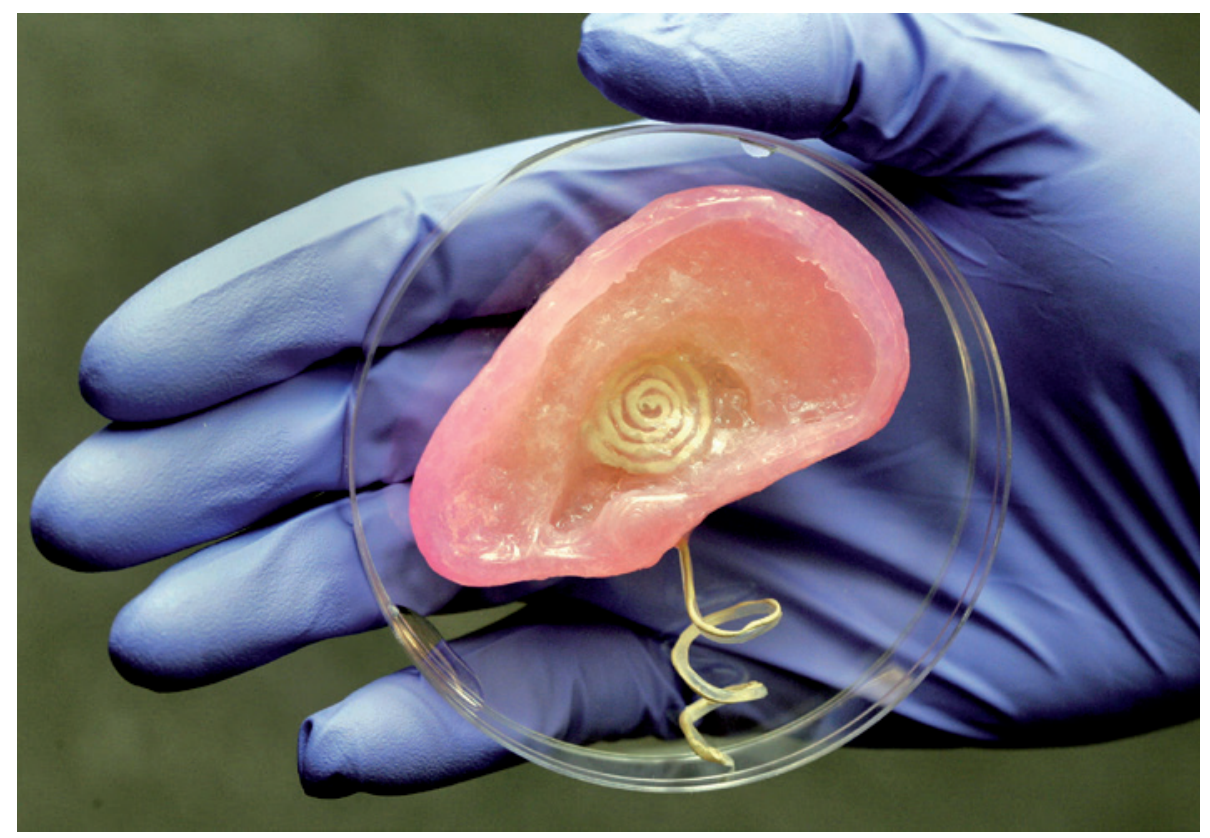

The increasing sophistication of 3D printing is shown in an ear that melds biological and electronic parts.

MATERIALS

\section{Printed body}

parts come alive

\section{Conference on 3D printing features made-to-order bones, and organs built using cells as 'ink'.}

\section{BY HEIDI LEDFORD}

$\mathrm{T}$ The advent of three-dimensional (3D) printing has generated a swell of interest in artificial organs meant to replace, or even enhance, human machinery.

Printed organs, such as a prototype outer ear developed by researchers at Princeton University in New Jersey and Johns Hopkins University in Baltimore, Maryland, will be on the agenda at the Inside 3D Printing conference in New York on 15-17 April. The ear is printed from a range of materials: a hydrogel to form an ear-shaped scaffold, cells that will grow to form cartilage, and silver nanoparticles to form an antenna (M. S. Mannoor et al. Nano Lett. 13, 2634-2639; 2013). The device is just one example of the increasing versatility of $3 \mathrm{D}$ printing.

The New York meeting, which bills itself as the largest event in the industry, will have plenty of widgets and novelties on display. But it will also feature serious discussions on the emerging market for printed body parts.

That business is

\section{$\rightarrow$ NATURE.COM}

For more printed parts, see:

go.nature.com/qsy61w currently focused on titanium replacement hip joints, which can be tailored to fit individual people, and made-to-order polymer bones to reconstruct damaged skulls and fingers. Printed body parts brought in US $\$ 537$ million last year, up about $30 \%$ on the previous year, says Terry Wohlers, president of Wohlers Associates, a business consultancy firm in Fort Collins, Colorado, that specializes in $3 \mathrm{D}$ printing.

Scientists are looking ahead to radical emerging technologies that use live cells as 'ink', assembling them layer-by-layer into rudimentary tissues, says Jennifer Lewis, a bioengineer at Harvard University in Cambridge, Massachusetts. Bioprinting firm Organovo of San Diego, California, already sells such tissues to researchers aiming to test experimental drugs for toxicity to liver cells. The company's next step will be to provide printed tissue patches to repair damaged livers in humans, says Organovo's chief executive, Keith Murphy.

Lewis hesitates to say that 3D printing will ever yield whole organs to relieve the shortage of kidneys and livers available for transplant. "I would love for that to be true," she says. "But these are highly complicated architectures." - 